\title{
Banana Fibers in Colonic Mucus May Puzzle the Endoscopist
}

S. D. Ladas' ${ }^{1}$ D. Polymeros ${ }^{1}$, C. Tzathas ${ }^{1}$, T. Emmanuel', H. Malamou ${ }^{2}$

${ }^{1}$ Hepato-Gastroenterology Unit, $2^{\text {nd }}$ Department of Internal Medicine, Medical School, Athens University, Attikon University General Hospital, Athens, Greece

2 Department of Medical Microbiology, G. Genimatas General Hospital, Athens, Greece

\section{Corresponding Author}

\section{S. D. Ladas, M.D.}

Hepato-Gastroenterology Unit Attikon University General Hospital 23 Sisini Street

11528 Athens

Greece

Fax: $\quad+30-210-7225882$

E-mail: sdladas@hol.gr
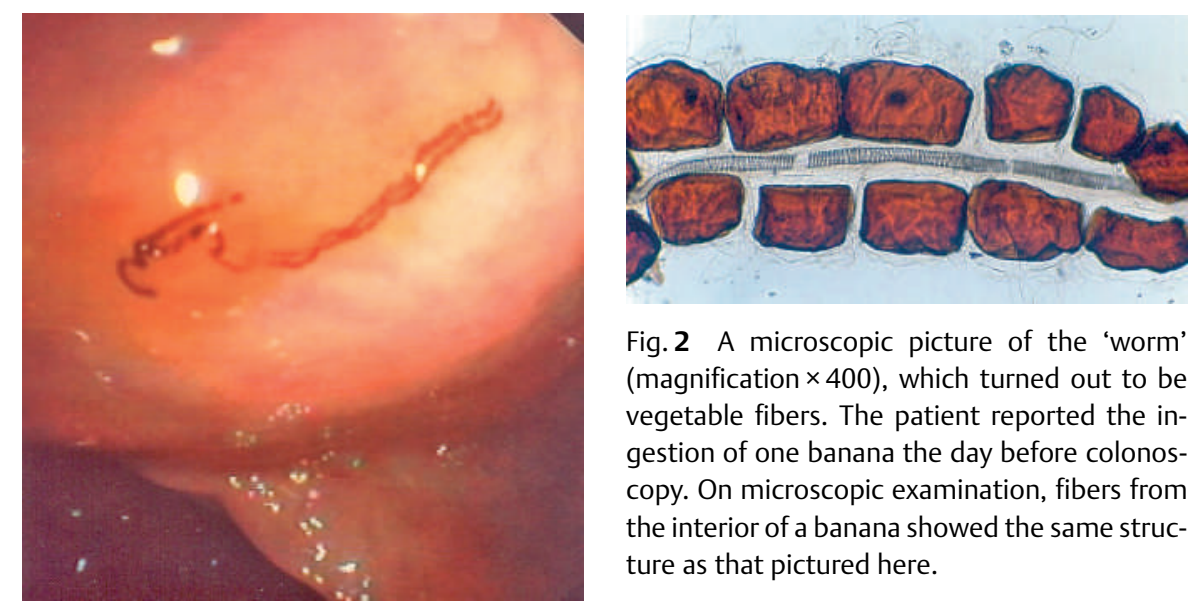

Fig. 2 A microscopic picture of the 'worm' (magnification $\times 400$ ), which turned out to be vegetable fibers. The patient reported the ingestion of one banana the day before colonoscopy. On microscopic examination, fibers from the interior of a banana showed the same structure as that pictured here.
Fig. 1 A 53-year-old woman was evaluated with colonoscopy for diarrhea. Bowel preparation was with sodium phosphate solution and the patient's having a liquid diet the day before colonoscopy. The colonic mucosa was normal, but odd filament-like, brown, immobile bands within mucus, measuring $1-3 \mathrm{~cm}$ in length, were noted in the transverse and the sigmoid colon. These resembled parasite or worm bodies, and one of them was grasped with the biopsy forceps and sent for microscopy within saline. 